\title{
Performance of the native predatory bug, Eocanthecona furcellata (Wolff) (Hemiptera: Pentatomidae), on the fall armyworm, Spodoptera frugiperda (J. E. Smith) (Lepidoptera: Noctuidae), and its limitation under field condition
}

\author{
M. C. Keerthi ${ }^{i^{*}} \mathbb{D}$, A. Sravika ${ }^{2}$, H. S. Mahesha ${ }^{1}$, Ankita Gupta ${ }^{2,3}$, H. A. Bhargavi ${ }^{1}$ and Shahid Ahmed ${ }^{1}$
}

\begin{abstract}
The invasive fall armyworm (FAW), Spodoptera frugiperda (J. E. Smith) (Lepidoptera: Noctuidae) was reported recently in India, in 2018, destroying food and fodder crops. Eocanthecona furcellata (Wolff) (Hemiptera: Pentatomidae), the native pentatomid predatory bug, expanded its host range by predating on larvae of FAW. The incidence of E. furcellata started during the 36th meteorological standard week and reached its peak population (3.4 adult and $2.4 \mathrm{egg}$ mass $/ \mathrm{m}^{2}$ ) during the 40th MSW. The predator adult female was capable of feeding on $126 \pm$ $4.76,88 \pm 1.37$, and $69 \pm 1.32$ larvae of $I I, I V$, and $\mathrm{VI}$ instars of $S$. frugiperda, respectively. The field performance of $E$. furcellata was narrowed due to the presence of platygastroid secondary parasitoids viz., Gryon sp., Telenomus sp., and Trissolcus sp. where rate of parasitism due to respective parasitoids reached up to 100, 91.80, and 77.68\% Autumn 2019.
\end{abstract}

Keywords: Spodoptera frugiperda, Eocanthecona furcellata, Performance, Rate of parasitism

\section{Background}

Invasive insect species poses major challenges to mankind by threatening food security, agricultural biodiversity, and human and animal health resulting in significant economic losses (Pimentel 2014). The fall armyworm (FAW) Spodoptera frugiperda (J. E. Smith) (Lepidoptera: Noctuidae) is a highly polyphagous, invasive lepidopteran pest native to tropical and subtropical regions of America. It has invaded the African continent in 2016 (Goergen et al. 2016) and later spread to countries in South and South-East Asia including India, Sri Lanka,

\footnotetext{
*Correspondence: Keerthimanikya@gmail.com; keerthi.mc@icar.gov.in ${ }^{1}$ Crop Improvement Division, ICAR-Indian Grassland and Fodder Research Institute, Jhansi, Uttar Pradesh 284003, India

Full list of author information is available at the end of the article
}

Bangladesh, China, Thailand, and Indonesia causing significant damage to food and fodder grasses (Sharanabasappa et al. 2018; Sun et al. 2019). Considering the ideal climatic conditions and year round availability of suitable host plants, the insect can complete several generations and the pest likely become endemic to the Indian subcontinent (Montezano et al. 2018).

Use of biocontrol agents has become one of the most feasible and economic tool to manage FAW. A wide range of natural enemies attacking FAW including parasitoids, arthropod predators, and entomopathogens were reported in India (Shylesha and Sravika 2018; Sharanabasappa et al. 2019). It is highly likely that native bio-agents of Spodoptera spp. might have expanded their host range by attacking S. frugiperda, a closely related foreign born insect 


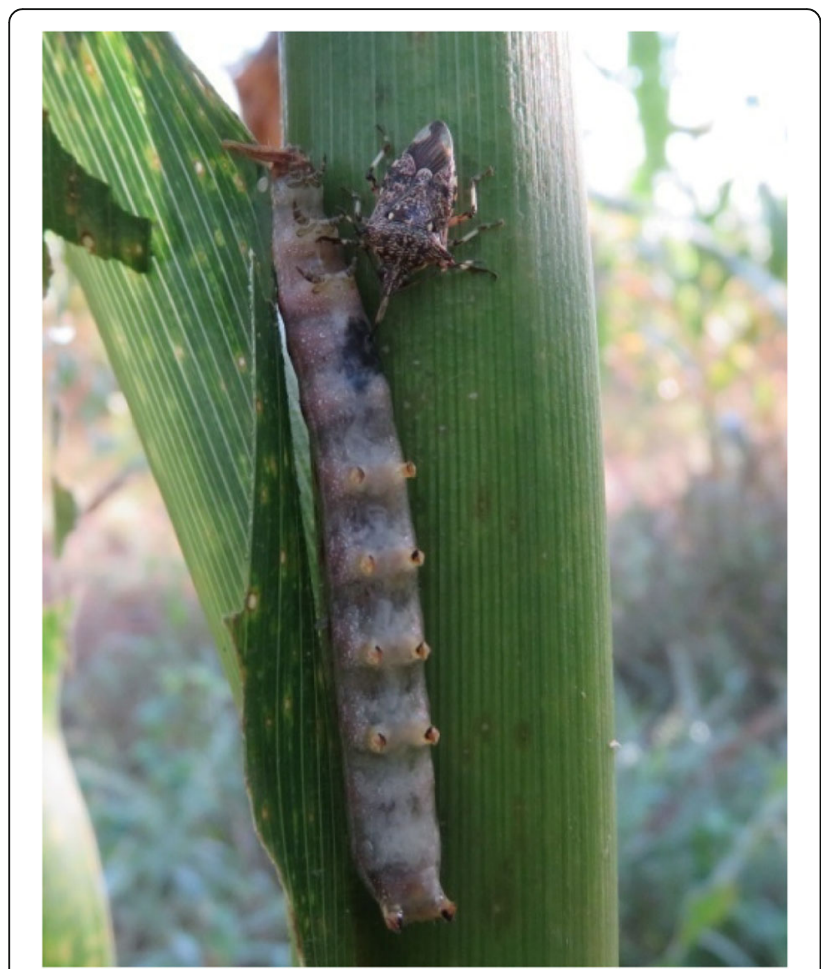

Fig. 1 Eocanthecona furcellata adult feeding on larvae of $S$. frugiperda (photo taken during the field survey: 16 October 2019)

(Sharanabasappa et al. 2019). The predators of FAW reported in India are generalist predators that attack many other caterpillars. Among them, the pentatomid bug, Eocanthecona furcellata (Wolff) (Hemiptera: Pentatomidae) is an effective predatory species widely distributed in Southeast Asian countries including India, China, Indonesia, and Japan (Shylesha and Sravika 2018) and commonly observed in cotton and chickpea ecosystem
(Nyunt 2008). In India, it has been identified as an important predator on Pericallia ricini (Lepidoptera: Arctiidae) (now known as Olepa ricini (Fabricius) on cotton (Nancy Shophiya and Sahayaraj 2014), Latoia lepida (Lepidoptera: Limacodidae) (now known as Parasa lepida (Cramer) (Senrayan 1988), Maruca vitrata (Fabricius) (Lepidoptera: Pyralidae), and Spodoptera litura Fabricius (Lepidoptera: Noctuidae) (Tiwari et al. 2017). The incidence of E. furcellata and feeding on FAW was observed (Fig. 1) at the Indian Council of Agricultural Research-Indian Grassland and Fodder Research Institute, Jhansi, Uttar Pradesh (25.526057 N, 78.571231 E), during Autumn 2019.

\section{Materials and methods}

In the present study, seasonal incidence of E. furcellata at ICAR-IGFRI, Jhansi, by visual counting the number of the predator, was recorded, and its egg masses in $1 \mathrm{~m}^{2}$ area in 5 random locations were replicated thrice. To study the predatory potential on S. frugiperda, the experiment was conducted at ICAR-National Bureau of Agricultural Insect Resources, during 2018-2019. The adults of $E$. furcellata were collected from maize fields and kept in plastic jar $(30 \times 25 \mathrm{~cm})$ with dried castor leaf as a substrate for oviposition. Four nymphal instars of the predator (excluding first nymphal stage: Zoophytophagous nature) were used to study predation rate on $S$. frugiperda. The individual nymphal instar $(n=10)$ of predatory bug viz., II, III, IV, and V, were placed in separate plastic container $(90 \mathrm{~mm} \times 50 \mathrm{~mm})$ along with 20 FAW larvae (II, IV, and VI instar) in each container for all the nymphal stage used. Before releasing of FAW larva, the head was crushed to stops their movement during predation. Numbers of larvae consumed by each nymphal instar were recorded daily, and fresh larvae were provided for further feeding till the end of each

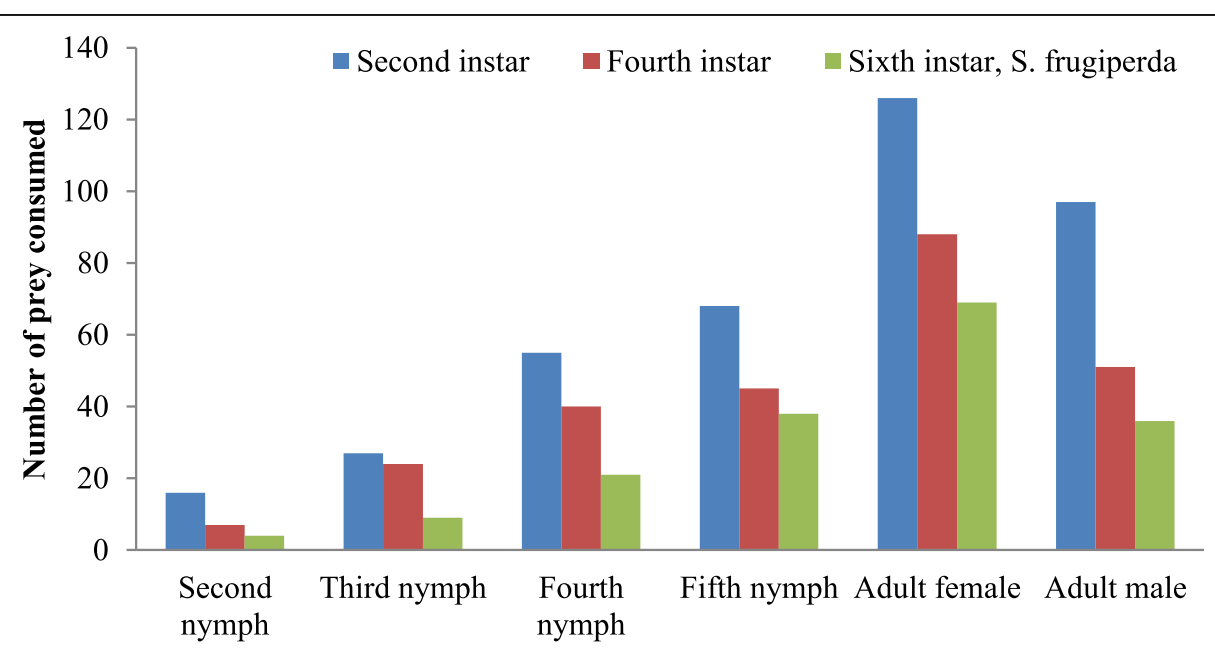

Stages of predator, E. furcellata

Fig. 2 Feeding potential of the predatory bug. E. furcellata on different larval instars of S. frugiperda 
nymphal instar of predator. Similar setup was repeated to study the feeding potential of E. furcellata adult, and the predation rate was recorded for the total adult longevity period (male 10 days and female 20 days). Each experiment was replicated thrice. During field visits (October 2019), the egg mass of E. furcellata (the eggs are bright black in color with shiny silver coating on surface; 12 spines surround the round top surface) was collected from maize field of IGFRI, Jhansi, and organic field of University of Agricultural Sciences, Bengaluru (13.082713 N, 77.576732 E), kept in laboratory for emergence. Normality and homogeneity check of the collected data were done, using SAS version 9.3. One way ANOVA was constructed using SAS and significance level judged at $P$ value $<0.05$.

\section{Results and discussion}

The incidence of E. furcellata started during the 36th meteorological standard week. The mean adult population and egg mass of E. furcellata were 1 and $0.6 / \mathrm{m}^{2}$, respectively, during the 37th meteorological standard week (MSW) and reached a peak of 3.4 (adult) and 2.4 (egg mass) $/ \mathrm{m}^{2}$ during the 40th MSW. Thereafter, the population started declining and attained lowest of 0.6 (adult) and 0.2 (egg mass $/ \mathrm{m}^{2}$ ) during the 47th MSW and disappeared during the 48th MSW, which coincided with the harvesting of maize crop in the field. Similar population dynamics of the predatory bug were reported by Snehel et al. (2017).

As illustrated in Fig. 2, adults showed more consumption rate to the nymphs under laboratory conditions $(\mathrm{df}$ $=2$, 27; $P<0.0001 ; F$ value: male $=733.31$; female $=$ 432.40; 2nd nymph $=263.2$; 3rd nymph $=261.56 ; 4$ th nymph $=496.14)$. The predation rate of the adult female was higher than the male. It consumed $126 \pm 4.76,88 \pm$ 1.37 , and $69 \pm 1.32$ of $2 \mathrm{nd}$, 4th, and 6th instars of $S$. frugiperda, respectively. Among the nymphs, the trend of predation gradually increased from the 2nd nymphal instar to the 5th in all the exposed larval instars. The 5th nymph has more potential than the rest of instars. It consumed $68 \pm 5.41,45 \pm 0.71$, and $38 \pm 1.03$ larvae of 2nd, 4th, and 6th instars of FAW. Obtained results are similar to those of Tuan et al. (2016) who reported that the female (N2-N3, N4, and N5) nymphs of E. furcellata consumed 7.6, 19.3, and 57.1 larvae of S. litura, respectively. The higher predation rate in female might be required to prepare for oogenesis and longevity in the adult stage. There were many reports of $E$. furcellata feeding on other lepidopteran caterpillars; however, literature on FAW is lacking hence the larvae of different taxonomic group used for comparisons.

A total of 6 egg masses of E. furcellata were collected from each location (Jhansi and Bengaluru), where number of eggs varied from 23 to 61 . Among the egg masses collected from Jhansi, 4 egg masses were found parasitizing with Telenomus sp. (Hymenoptera: Platygastridae)
(Fig. 3a); the remaining 2 were parasitized by Gryon sp. (Hymenoptera: Platygastridae) (Fig. 3b). The percent parasitism of Telenomus sp. varied from 78.26 to $91.80 \%$, whereas percent parasitism by Gryon sp. was 65.11 and 71.69, respectively, from 2 egg masses. On the other hand, among the egg masses collected from Bengaluru, one egg mass was parasitized by Trissolcus sp. (Hymenoptera: Scelionidae) (Fig. 3c) and 2 egg masses were parasitized by Gryon sp. The percent parasitism of Trissolcus sp. was $77.78 \%$ and 85.18 and $100 \%$ by Gryon
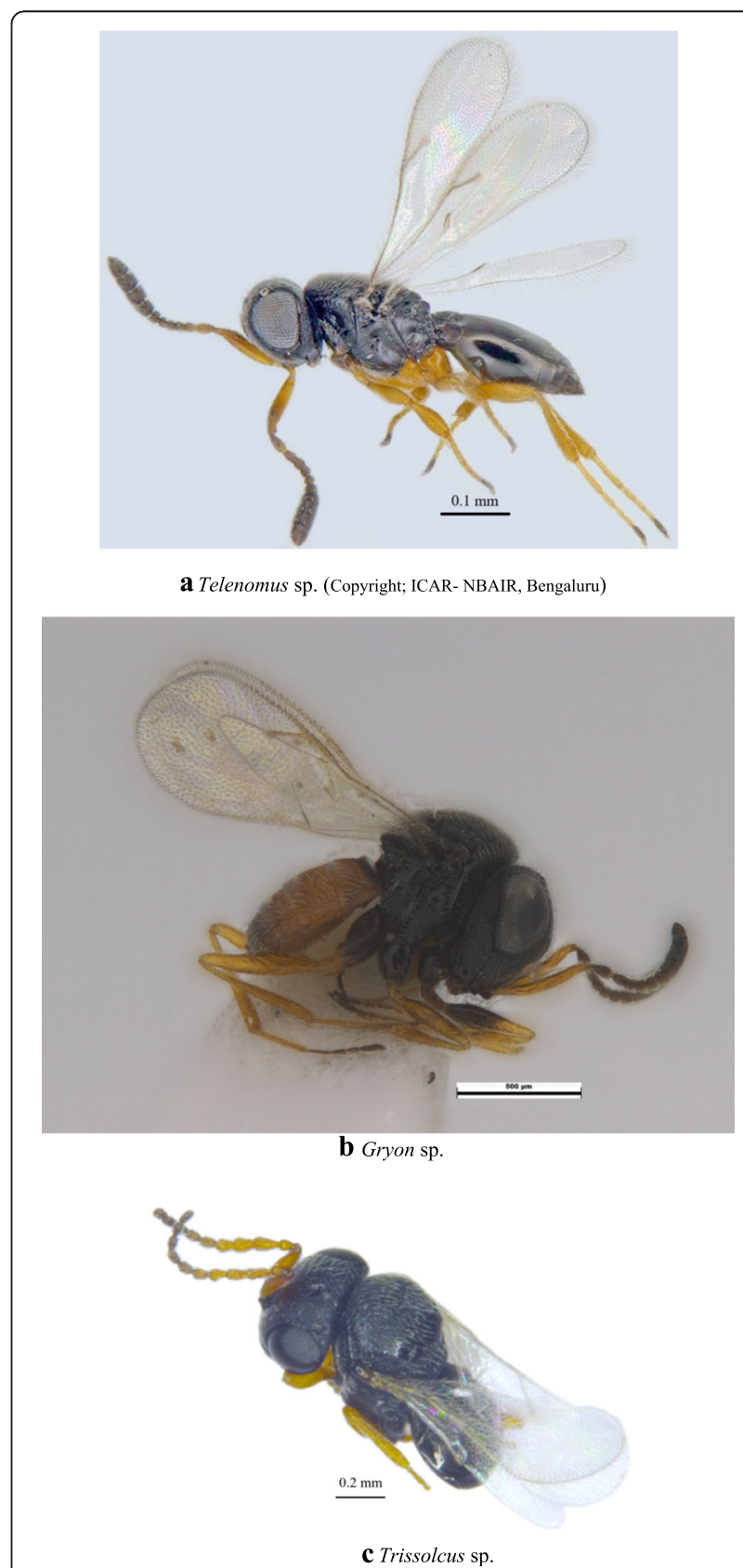

Fig. 3 a Telenomus sp. (copyright; ICAR-NBAIR, Bengaluru). b Gryon sp. c Trissolcus sp. 
sp., respectively, from 2 egg masses. Gryon sp. was the common egg parasitoid observed in both locations. Interestingly, all the adult parasitoids (Gryon and Trissolcus) emerged from egg masses were males, except for Telenomus sp. where females also were obtained.

The role of insects in any ecosystem has always varied depending on human choice, because Gryon sp., Trissolcus sp., and Telenomus sp. were important egg parasitoids commonly used around the world for the management of hemipteran bugs (Cornelius et al. 2016; Buffington et al. 2018); however, in the present study, they were found parasitizing eggs of the predatory bug, E. furcellata, which plays a role of predator in maize ecosystem. The result of the current study indicates the role of E. furcellata, as a biocontrol agent; however, under field conditions, it is assumed that its potential might be limited by existing secondary parasitoids. In the current study, E. furcellata is not only effective in reducing FAW but also in managing other lepidopteran pests of maize like Helicoverpa armigera (Hübner), Spodoptera litura, and Ostrinia furnacalis (Guene) (Semillano and Corey 1992; Nebapure and Meena 2011). However, the efficiency of the predator is not fully expressed in nature due to existing native secondary parasitoids like Gryon sp., Trissolcus sp., and Telenomus sp. The presence of such secondary parasitoids in nature may limit the potential of the predator. Therefore, further field studies are required to confirm the hypothesis and for better understanding the functioning of the food web, as multi-trophic level systems where secondary parasitoids are common, even in simple agricultural ecosystems such as greenhouses.

\section{Abbreviations}

FAW: Fall armyworm; ICAR: Indian Council of Agricultural Research; IGFRI: Indian Grassland and Fodder Research Institute; MSW: Meteorological standard weeks; Fig.: Figure; NBAIR: National Bureau of Agricultural Insect Resources; UAS, GKVK: University of Agricultural Sciences, Gandhi Krishi Vigyana Kendra

\section{Acknowledgements}

The authors are thankful to the Indian Council of Agricultural Research, Dr. V. K. Yadav, Director ICAR-IGFRI, and Dr. C. R. Ballal, Director ICAR-NBAIR, Bengaluru.

\section{Authors' contributions}

KMC and AS: conceptualization, experimentation, and original draft writing. MHS: data curation. AG: identification of hyperparasitoids and manuscript editing. BHA and SA: statistical analysis and reviewing and editing. All authors read and approved the final manuscript.

\section{Funding}

No funding received

\section{Availability of data and materials}

All data are available in the manuscript.

Ethics approval and consent to participate

Not applicable

Consent for publication

Not applicable

Competing interests

The authors declare that they have no competing interests

\section{Author details}

${ }^{1}$ Crop Improvement Division, ICAR-Indian Grassland and Fodder Research Institute, Jhansi, Uttar Pradesh 284003, India. ${ }^{2}$ CAR-National Bureau of Agricultural Insect Resources, Bengaluru, Karnataka, India. ${ }^{3}$ Division of Germplasm Collection and Characterization, ICAR-NBAIR, Bengaluru, Karnataka, India.

Received: 16 March 2020 Accepted: 25 May 2020

Published online: 04 June 2020

References

Buffington ML, Talamas EJ, Hoelmer KA (2018) Team Trissolcus: integrating taxonomy and biological control to combat the brown marmorated stink bug. Am Entomol 64:224-232

Cornelius ML, Buffington ML, Talamas EJ, Gates MW (2016) Impact of the egg parasitoid, Gryon pennsylvanicum (Hymenoptera: Scelionidae), on sentinel and wild egg masses of the squash bug (Hemiptera: Coreidae) in Maryland. Environ Entomol 45:367-375

Goergen G, Kumar PL, Sankung SB, Togola A, Tamò M (2016) First report of outbreaks of the fall armyworm Spodoptera frugiperda (JE Smith) (Lepidoptera: Noctuidae), a new alien invasive pest in West and Central Africa. PloS One 11(10)

Montezano DG, Specht A, Sosa-Gómez DR, Roque-Specht VF, Sousa-Silva JC, SVD P-M, Peterson JA, Hunt TE (2018) Host plants of Spodoptera frugiperda (Lepidoptera: Noctuidae) in the Americas. Afr Entomol 26:286-300

Nancy Shophiya J, Sahayaraj K (2014) Biocontrol potential of entomophagous predator Eocanthecona furcellata (Wolff) against Pericallia ricini (Fab.) larvae. Int J Curr Res 6(10):9052-9056

Nebapure SM, Meena A (2011) Canthecona furcellata: a predator of Maruca vitrata. Ann PI Protec Sci 19:451-508

Nyunt KT (2008) Potential of the predatory pentatomid Eocanthecona furcellata (Wolff) as a biocontrol agent on American boll worm in cotton in Myanmar. Ph.D. Agr. Thesis at Georg-August University, Gottingen, Germany.

Pimentel D (2014) Biological invasions: Economic and environmental costs of alien plant, animal, and microbe species. CRC press.

Semillano NS, Corey FM (1992) Life history of the predatory bug (Eocanthecone furcellata Wolff) using the larvae of two lepidopterous insect pests as host. CMU J Sci (Philippines) 5(1):16-33

Senrayan R (1988) Functional response of Eocanthecona furcellata (Wolff) (Heteroptera: Pentatomidae) in relation to prey Latoia lepida (Cramer) (Lepidoptera: Limacodidae). Proc Indian Acad Sci (Animal Science) 97:339-345

Sharanabasappa KCM, Asokan R, Swamy HM, Maruthi MS, Pavithra HB, Hegde K, Navi S, Prabhu ST, Goergen G (2018) First report of the fall armyworm, Spodoptera frugiperda (JE Smith) (Lepidoptera: Noctuidae), an alien invasive pest on maize in India. Pest Manag Hort Ecosyst 24(1):23-29

Sharanabasappa KCM, Poorani J, Maruthi M, Pavithra HB, Diraviam J (2019) Natural enemies of Spodoptera frugiperda (JE Smith) (Lepidoptera: Noctuidae), a recent invasive pest on maize in south India. Fla Entomol 102(3):619-623

Shylesha AN, Sravika A (2018) Natural occurrence of predatory bugs, Eocanthecona furcellata (Wolff) and Andrallus spinidens (Fabr.) on Spodoptera frugiperda (Smith) (Hemiptera: Pentatomidae) in maize and their potential in management of fall army worm. J Biol Control 32(3):209-211

Snehel C, Meena A, Jagdish J (2017) Seasonal abundance of predatory bugs, Eocanthecona furcellata (Wolff) and Rhynocoris fuscipes (F) and its olfactory responses towards plant and pest mediated semiochemical cues in Pigeonpea ecosystem. Legume Res 40(2):351-357

Sun XX, Hu CX, Jia HR, Wu QL, Shen XJ, Zhao SY, Jiang YY, Wu KM (2019) Case study on the first immigration of fall armyworm, Spodoptera frugiperda invading into China. J Integr Agr 18:2-10

Tiwari S, Maurya RP, Pandey AK (2017) Effect of different insect hosts on biology and predation efficiency of Eocanthecona furcellata (Wolff) (Hemiptera: Pentatomidae). Bioscan 12(1):193-197

Tuan SJ, Yeh CC, Atlihan R, Chi H (2016) Linking life table and predation rate for biological control: a comparative study of Eocanthecona furcellata (Hemiptera: Pentatomidae) fed on Spodoptera litura (Lepidoptera: Noctuidae) and Plutella xylostella (Lepidoptera: Plutellidae). J Eco Entomol 109:13-24

\section{Publisher's Note}

Springer Nature remains neutral with regard to jurisdictional claims in published maps and institutional affiliations. 